In Evolution of Marine Coastal Ecosystems under the Pressure of Global Changes. Proceedings of Coast Bordeaux Symposium and of the 17th French-Japanese Oceanography Symposium, pp. 441456

Eds H.-J. Ceccaldi et al.

2020,

ISBN 9783030434830

https://doi.org/10.1007/978-3-030-43484-7 30

https://archimer.ifremer.fr/doc/00634/74602/

\title{
Regional Schemes for the Development of Marine Aquaculture (SRDAM) and Access to New Farming Sites on the French Mediterranean Coast
}

\author{
Mariojouls Catherine ${ }^{1,{ }^{*}}$, Girard Sophie ${ }^{2}$
}

${ }^{1}$ AgroParisTech, UMR SAD-APT, Université Paris-Saclay Paris, France

2 IFREMER, UMR AMURE Plouzané, France

* Corresponding author : Catherine Mariojouls, email address : catherine.mariojouls@agroparistech.fr

\begin{abstract}
:
In France, the absence of further development of marine fish farming over the last 20 years has been attributed to regulatory constraints, and to the difficult access to new farming sites, due to high competition between different uses in the coastal zone, and to the shortcomings of governance in these areas. The regional schemes for the development of marine aquaculture (SRDAM) were introduced by the French Law on modernization of agriculture and fisheries (LMAP, July 27, 2010). The goals of SRDAMs are to make an inventory of existing aquaculture sites and to identify potential sites suitable for aquaculture, and to conciliate the development of marine aquaculture with other coastal activities. They are expected to allow access to new fish farming sites. Our study focuses on the three SRDAMs on French Mediterranean coast, in order to investigate to which extent the SRDAMs offer opportunities for a new development of marine fish farming, in line with the quantified objectives of the French national strategic plan for the development of sustainable aquaculture. Based on desk work and on enquiries with professional representatives, administration, and experts, our study aims to analyze the building process and the results of SRDAMs and discusses the constraints to an extension of marine fish farming.
\end{abstract}

Keywords : Marine fish farming, Marine spatial planning 


\section{Introduction}

Despite a long coastal zone $(5850 \mathrm{~km}$ on metropolitan territory, $18,300 \mathrm{~km}$ in total with overseas territories, Estimation $\left.\mathrm{SHOM}^{1}, 1999\right)$, France has a limited development of marine fish farming, representing only 4,920 tons in 2016 (source CIPA $^{2}$ ). The absence of further development of marine fish farming over the last 20 years has been attributed to the difficult access to new farming sites, due to high competition between different uses in the coastal zone and shortcomings of governance in these areas, to regulatory constraints and to a lack of social acceptability. At EU level, "improving access to space and water" is one of the four priorities defined in the Strategic Guidelines for the Sustainable Development of EU Aquaculture, and focused by the Member States' plans when developing Multiannual National Strategic Plans for the promotion of sustainable aquaculture and related operational programs for the $\mathrm{EMFF}^{3}$ (2014-2020). The quantified objectives of the French NSPA ${ }^{4}$ are particularly ambitious for marine fish farming and target a production ranging from 10,000 tons to 20,000 tons (lower and higher hypothesis).

In France, the Regional schemes for the development of marine aquaculture (SRDAM ${ }^{5}$ ) were introduced by the French Law on modernisation of agriculture and fisheries (LMAP ${ }^{6}, 27^{\text {th }}$ July 2010). The goals of SRDAM are to make an inventory of existing aquaculture sites and to identify potential sites suitable for aquaculture, and to conciliate the development of marine aquaculture with other coastal activities or uses. As a tool for spatial planning, they are expected to improve the access to new fish farming sites.

In 2016, marine fish farming sector in France produced 4,920 tons, among which 1,928 tons of seabass (Dicentrarchus labrax), 1,671 tons of seabream (Sparus aurata) and 236 tons of meager (Argyrosomus regius)

${ }^{1}$ SHOM: Service Hydrographique et Océanographique de la Marine,

${ }^{2}$ CIPA: Comité Interprofessionnel des produits de l'aquaculture http://www.poisson-aquaculture.fr/le-cipa/

${ }^{3}$ EMFF: European Maritime and Fisheries Fund

${ }^{4}$ MEDDED (updated December 2015). Plan Stratégique National: Développement des aquacultures durables 2020

- France. https://ec.europa.eu/fisheries/cfp/aquaculture/multiannual-national-plans

${ }^{5}$ SRDAM (Schéma régionaux de développement de l'aquaculture marine) : Regional scheme for the development of marine aquaculture

${ }^{6}$ LMAP (Loi de modernisation de l'agriculture et de la pêche) : Law for modernization of aquaculture and fisheries 
(source CIPA). About half of the marine farmed fish are produced on the Mediterranean coast, in 20 farms in 2009 (source DIRM). The Mediterranean fish farms mainly focus on growing seabass, seabream and meager in cages in coastal areas. According to Mare I Stagni, the syndicate of Corsican aquaculturists, in 2017 Corsica alone produced 1,700 tons in 8 farms.

The SRDAMs for the three Mediterranean administrative regions: Provence - Alpes Cote d'Azur (PACA), Languedoc Roussillon (LR), and Corsica, were approved in 2015. We investigated whether the SRDAMs could provide a room for improvement of the development of marine fish farming on Mediterranean coastal zones. The objectives of our study are (i) to understand the building and the contents of the SRDAMS; (ii) to look at the changes occurred after the publication of SRDAMs in 2015 and (iii) to analyze the other constraints to a further growth of marine fish farming. While SRDAMs apply to all aquaculture, our study focuses only marine fish farming.

\section{Methods}

The present study included desk work and interviews. We analyzed the available documents about SRDAMs and other planning documents, and scientific literature. From June to November 2017, we carried out 13 interviews (1 to 2 hours each) following a semi-directive guide, with several types of actors : 5 representatives of national administration (2 at national scale, one at inter-regional scale -DIRM ${ }^{7}$ Méditerranée-, and 2 in the Corsica region -DDTM ${ }^{8}$ South Corsica, DREAL-); one representative of Region Corsica administration; 4 key-actors and representatives in the fish farming sector $\left(2 \mathrm{CEO}^{9}\right.$ of the two main marine fish farming companies in France, one for the professional body SFAM (syndicate for marine fish farmers, and one for the syndicate of Corsican aquaculturists); 3 researchers ( 2 in IFREMER, 1 in University of Corte).

The semi-directive guide was organized in four groups of questions, concerning : the elaboration of the SRDAMs and the role played for it; the changes introduced by the SRDAMs in the development of marine fish farming sector; the constraints, other than access to farming sites, limiting the growth of this sector; the possible contribution of SRDAMs to marine spatial planning.

\section{Description of the SRDAMs}

\subsection{General features}

The SRDAMs are guidance and management documents for marine aquaculture, that have been introduced by the French Law on modernisation of agriculture and fisheries (LMAP) the 27 July 2010, and then integrated into the French Rural and Fishing Code. According to the Article D 923-2, The SRDAMs apply to the public maritime domain and to the waters under French jurisdiction, and also to the territory of coastal municipalities. The SRDAMS should inventory exhaustively the existing aquaculture sites and the sites conducive to the development of marine sustainable aquaculture, including the access routes and also the terrestrial surfaces required for their exploitation. The identification of suitable ${ }^{10}$ sites is based notably on the assessment of different characteristics (see below) and takes into account the environmental impacts and socio-economic benefits that the activity is likely to create, on the basis of estimated production.

So the SRDAMs include a double inventory: (i) an inventory of existing aquaculture sites, for all types of aquaculture (shellfish, fish, algae, etc); (ii) an inventory of suitable sites for the creation of new aquaculture farms, in order to ensure a development of marine aquaculture, in harmony with other coastal activities. The identification of suitable sites should be based on a minimum consensus between the concerned stakeholders.

The territorial scope is specified by the decree $\mathrm{n}^{\circ}$ 2011-888 of July 26, 2011: the perimeter concerned by these schemes is the maritime public domain and the territory of coastal municipalities. This decree was completed by an administrative circular which describes the implementation and development methods for the SRDAMs.

\footnotetext{
${ }^{7}$ DIRM: Direction Interrégionale de la Mer

${ }^{8}$ DDTM: Direction Départementale des Territoires et de la Mer

${ }^{9}$ CEO : Chief Executive Officer

${ }^{10}$ We use the English word "suitable" to translate the French "propice"
} 
Once adopted by order of the regional prefect, the SRDAM provides a general spatial plan that must be taken into account during the administrative examination of each application for aquaculture concessions located on the public maritime domain. However, the set of procedures (environmental impact assessment, and Natura 2000 impact assessment in particular) foreseen in the framework of authorization for fish farming, remains necessary. The SRDAMs are also intended to be considered when preparing the DSF ${ }^{\mathbf{1 1}}$ (Document Stratégique de Façade), which are strategic documents for implementing the integrated maritime policy, including the maritime spatial planning (MSP). But, as underlined in the Mediterranean SRDAMs reports, the SRDAMs are evolving and flexible documents which are expected to be revised every five years. At revision, some options different from the previous elaboration may be taken, concerning the targeted sites (including or not the landing sites on shore), the criteria and thresholds considered for site selection, and the farming techniques.

\subsection{The process for drawing up the Mediterranean SRDAMs}

The Interregional Directorate for the Sea (DIRM) for Mediterranean coast was in charge, under the authority of each Region Prefect, of the elaboration of the three regional aquaculture plans concerning the Mediterranean coast. This was carried out in close collaboration with the departmental directorates of territories and sea (DDTMs) and benefited from the scientific and technical support of the Ifremer Méditerranée and of the CEREMA ${ }^{12}$.

The method adopted for the three Mediterranean regions was based on six successive steps:

$\checkmark \quad$ First concertation phase, including 3 steps : (i) collection of information and data from the State services and from aquaculture professionals; (ii) elaboration of projects of two directory (existing sites, suitable sites); (iii) regional working meetings between State services, professionals (aquaculture) or their representatives, regional territorial collectivity,

$\checkmark \quad$ Written consultation about a first draft of SRDAM: of the public services and of the public institutes; of the professional bodies concerned by SRDAM (aquaculture, capture fisheries); of the territorial collectivities at regional and departmental scales,

$\checkmark$ Concertation meeting (or several meetings) with stakeholders (elected representatives of territorial collectivities, representatives of public bodies, representatives of concerned professionals, qualified persons -from associations or NGO- chosen for their capacities as for protection of environment or sea and coastal uses); and consultation of the Maritime Façade Council;

$\checkmark$ Elaboration of the environmental evaluation of SRDAM, and submission to the Environmental Authority for advice;

$\checkmark \quad$ Consultation of the public (SRDAM available on website during one month);

$\checkmark$ Adoption of the SRDAM by the regional prefect.

Two directories were elaborated in the SRDAMs:

1/ The directory of existing aquaculture sites was carried out with data collected from DDTMs and from professionals.

2/ The directory of sites suitable for the development of marine aquaculture. It was the subject of a planning process starting from the inventory of sites proposed by the professionals, crossed with several categories of geolocalised data, such as:

$\checkmark$ physical or environmental data required to assess the feasibility of fish or shellfish farming activities :

- $\quad$ at sea: depth, wind, swell, water quality, distance to coast, distance to landing point,

- onshore: distance to coastline, present land uses, underground water resources, maximum altitude, zone with technological risks

$\checkmark$ data referring to other uses and potential conflict uses: navigation (all types, including in particular fishing), air traffic, mooring zones

$\checkmark$ data related to the protection of natural environment: existing protected zones (MPA...), zones with vulnerable benthic biocoenosis (Posidinia meadows, coralligenous etc.)

All these data contributed to the selection of suitable sites for aquaculture, or helped eliminate or reduce the perimeter of certain suitable sites. The selection and mapping of suitable sites also benefited from scientific expertise and previous works on the subject, in particular the Ifremer document about the potential sites for

${ }^{11}$ DSF: Document Stratégique de Façade, i.e. Strategic document for a marine region
${ }_{12}$ Center for Studies and Expertise on Risks, Environment, Mobility and development. 
aquaculture (1999) and a GIS ${ }^{13}$ tool applied to the development of Corsican marine fish farming in floating cages (SI REMCO ${ }^{14}$, Ifremer 2007).

In addition to mapping, the SRDAMs have also a strategic dimension. The Mediterranean SRDAMs aim at doubling the present production, which is coherent with the low hypothesis of the French Multiannual National Strategic Plan issued in 2015. In this first edition, they have been designed in continuity with the structure of the present fish farming sector: the considered techniques are marine net pen cages near shore (no offshore marine fish farming) and fish farms on shore, and the SRDAM for the Region PACA explicitly focuses on small to medium scale farms.

\subsection{Corsica: a particular case}

Regarding the planning of aquaculture in coastal zone, the situation in Corsica is different from that of inland regions like Languedoc-Roussillon and PACA. Actually, the Region of Corsica began early, in the 2000s, to work on the potential sites for aquaculture, and so had already an important data base and methodological basis for mapping the suitable sites for aquaculture. Another important point is that the preparation of SRDAM was simultaneous and congruous with the preparation of the PADDUC ${ }^{15}$, a document defined in the Article 12 of the Law of 22nd January 2002 concerning Corsica. The latter has the value of a territorial land planning Directive. Accordingly the PADDUC shall prevail against any other land planning documents, which means that it provides a stronger legal framework than a SRDAM for the maps related to aquaculture zones.

Within the PADDUC, the part dedicated to coastal zones corresponds to a SMVM ${ }^{16}$. The final report for the SMVM, resulting from in-depth studies and consultations, includes several detailed maps for issues, threats, potentialities and vocations. It is interesting to note that the vocation map quotes the possible activities (or the only possible activity in the case of "exclusive vocation"), with several levels of priority (3 levels for maritime space, 2 levels for coastal land). So for aquaculture, the SMVM vocation map provides a detailed framework for public decision-making.

The PADDUC presents marine fish farming as a key and promising activity for the economy of Corsica, today being the second exporting activity after citrus, with $95 \%$ of Corsican farmed fish either exported or sold in mainland France. The production of aquaculture is expected to increase threefold compared to the current production in 5 years (i.e. reaching 5,000 tons), and there is a clear political will to support this growth. It must be recalled that Corsica presents very good natural conditions for fish farming development (high water quality, long coastline) and is regarded as the French Mediterranean region with the most important potential for marine fish farming growth. Particularly in Corsica, rich in remarkable natural habitats, the environmental issues have been taken into account in the studies and the consultations, leading to the mappings prepared in PADDUC, and in the SRDAM. Finally, we can underline that the PADDUC and the SRDAM published in 2015 constitute a very favorable framework for a development of aquaculture in Corsica.

\subsection{The scope of the SRDAMs}

The Mediterranean SRDAMs in their strategic aspects aim to double the current production. To achieve this objective, the number of selected suitable sites is not very high (Table 1). It can be underlined that the state of mind of the fish farmers consulted during the process was not to ask for a great number of potential sites, but a number allowing a reasonable growth of their activity.

Table 1: Number of sites considered for marine fish farming in the three Mediterranean regions (Source: SRDAMs of the three regions)

\begin{tabular}{|l|c|c|}
\hline Regional scheme & Number of existing sites & Number of identified suitable sites \\
\hline $\begin{array}{l}\text { SRDAM Languedoc-Roussillon } \\
\text { (new Region Occitanie) }\end{array}$ & 5 & 17 \\
\hline $\begin{array}{l}\text { SRDAM PACA (Provence, Alpes, } \\
\text { Côte d'Azur) }\end{array}$ & 15 & 10 \\
\hline SRDAM Corse & $8(+1$ for research) & 14 \\
\hline
\end{tabular}

\footnotetext{
${ }^{13}$ GIS: Groupement d'intérêt scientifique

${ }^{14}$ SI REMCO : Système d'Information pour l'exploitation durable des REssources Marines COrses

${ }^{15}$ PADDUC (Plan d'aménagement et de développement durable de la Corse), i.e. the Plan for land management and sustainable development in Corsica - approved in 2015

${ }^{16}$ SMVM : Schéma de Mise en Valeur de la Mer i.e. « Scheme for valorization of the sea »
} 


\section{Results: analysis of interviews}

\subsection{Analysis of the building process \\ 4.1.1. An important input from the DIRM Méditerranée}

The DIRM Méditerranée achieved a very important work to build the three SRDAMs. From 2011 to 2015, the work done is equivalent to two years of a full-time equivalent.

The aims in elaborating SRDAMs in Mediterranean regions include not only the final mapping of suitable sites, but also the writing of a strategic document for a sustainable aquaculture development, taking into account all other uses and issues. The elaboration of SRDAMs was based on a clear willing to consult the users of the coastal zone, or their representatives, through a progressively broadening approach. A first concertation phase took place with a "first circle" of stakeholders (aquaculture professionals, IFREMER, concerned public administration DDTMs, OEC) for the elaboration of a first draft, submitted then through written consultation to a "second circle" (other public administrations, mayors of local municipalities, public bodies). This was followed by concertation meetings on a wide basis (territorial collectivities, public bodies, concerned professionals, qualified persons from associations or NGO) and by a public consultation on internet.

Beforehand, many bilateral meetings had been organized, which contributed to low down the tensions before the official meetings and made possible to find a consensus. In Corsica, a similar work was done locally for preparing the PADDUC and so benefited to the drawing up of the SRDAM, and reciprocally.

\subsubsection{A great involvement from the marine fish farming sector}

The marine fish farmers, through their national syndicate SFAM and local fish farmers as representatives, were involved in the SRDAM process, providing information and data, and being consulted on the choice of criteria. Importantly, in each region the directory of suitable sites was based first on proposals from professionals, before crossing with other issues. Unanimously, interviewed professionals declared that they were very involved in the preparation of SRDAMs, and were satisfied with the results that took into account their wishes and advices. Nevertheless, they also underlined that the time necessary for participating to the building of SRDAM was very important for professional representatives, and difficult to find for companies.

\subsubsection{A process longer than expected}

Although the circular from DPMA (2011) mentioned that the SRDAMs should be drawn up in few months, it finally took about 4 years to finish the Mediterranean SRDAMs. Not only it was the first attempt to map aquaculture sites exhaustively (except Ifremer's study in 1999, but at lower precision), but a lot of unforeseen difficulties, notably methodological, appeared.

\subsection{Methodological lessons brought by the SRDAMs building}

The SRDAMs represented the first opportunity to gather and process a great amount of data required to characterize the different uses and the environment. The work done by IFREMER in Corsica (SI REMCO, 2007) provided a first methodological framework for data bases and GIS, and was completed by adding other criteria. But despite this methodological basis, the experience of building SRDAMs brought out the difficulties inherent to a spatial planning in coastal area, notably some shortcomings in available data and the need for further homogeneity of data sources. For this first edition of the three Mediterranean SRDAMs, it was decided to restrict the criteria to a common list for which the approach could be homogeneous.

Moreover, while initially the SRDAMs were expected to allow a mapping for aquaculture with an average precision, after the submission of the first draft to the "second circle", especially mayors, it became obvious that a finer precision was needed. Actually, for the various uses already existing in the coastal zone, an average precision was not enough to plan their own activity or to solve conflicts with other users. This experience confirmed that key questions for MSP, at least in coastal areas, will be the scale for data and the accuracy of mapping.

The SRDAMs thus appear as a first step for setting up a methodology for spatial planning in coastal zone.

\subsection{Some missing points in SRDAMs}

The professionals mentioned clearly two weaknesses in the concept of SRDAMs. One is the weak legal value of SRDAMs, as they cannot prevail against other planning documents. Even in Corsica, where the PADDUC provides a stronger framework concerning that aspect, no new projects have emerged since 2015. We shall discuss later the key issue of conditions for a successful allocation of space for aquaculture. 
The other point is the absence of land-based sites for aquaculture companies in Mediterranean SRDAMs. The land-based sites are key components of aquaculture operations and need to be considered also in planning documents, because land coastal zone is also a place of high conflicts between users. An example of the difficulty to work without dedicated zone for land-based facility can be found today in Corsica in the bay of Ajaccio: after decades, a large farm has not yet obtained the right to build land-based facilities and is obliged to work in abnormal conditions.

\subsection{Development of marine fish farming after SRDAMs publication?}

Two years after that the three Mediterranean SRDAMs were published, there have been no new projects of fish farming. Despite the relatively short period of time, it thus seems that the access to new sites is not the main obstacle to development, and our interviews show that other issues are at stake.

Most interviewees mentioned spontaneously the administrative burden concerning the application files for fish farming authorization as the main constraint for development. It represents a lot of files to fill in, is very timeconsuming and is a source of uncertainty for professionals. It is also cause of abandon for some projects prepared by small companies.

Financial or economic factors were also questioned. The interviewed professionals indicated that there are investors interested in aquaculture projects, but the difficulty to create new farms in France already made some of them invest in other countries with more favorable conditions regarding access to farming sites, as for administrative procedure and availability. Banks and public support for marine fish farming do exist; sometimes slow, the financing support could be improved. The market is not either regarded as a limiting factor for the development of marine fish farming. The professionals mentioned that the French market would accept more French products sold at prices higher than imported seabass and seabream, as long as the total French production "does not reach very high level". The corresponding production level (threshold) could not be estimated by interviews and would therefore require further investigation. Some segmentation through origin label is also wished by some marine fish farmers.

More widely, the issue at stake remains the lack of social acceptability that strikes aquaculture. While the French fish farmers hoped initially that SRDAMs would improve the social acceptability of aquaculture, the absence of further development two years after the SRDAMs publication is a cause of a great disappointment among the fish farmers. Interestingly, the launching of SRDAMs was perceived by the fish farmers as a very positive sign: politically, it was interpreted as a recognition and a mark of attention for their sector. A great expectation was placed in the SRDAMs, as a tool for enhancing the access to new sites and a way to improve the social acceptability of aquaculture. This positive interpretation played a role in the important involvement of fish farmers in the elaboration of SRDAMs. The initial expectation of fish farmers relied to some extent on a misunderstanding about the goal of the SRDAM, but the consequence is now some skepticism towards the future spatial planning tools.

\subsection{The future Marine Spatial Planning}

For all interviewees it was clear that SRDAMs are one step on the way to elaborate a maritime spatial planning. The SRDAMs will be included in the Maritime Spatial Planning due for 2021, presently prepared by DIRMs in the framework of DSF, the French framework for integrated maritime policy and maritime spatial planning.

For marine aquaculture, the French Government launched in 2016 the $\mathrm{MEAP}^{17}$ (best sites for aquaculture) as a step following SRDAMs. It was the subject of a working group gathering professionals, administration and research. The aim would be to develop an interactive mapping tool for choosing the best sites for aquaculture. A feasibility study was carried out by consultants in 2017. It has not been put in application since then.

\section{Discussion}

The publication of Mediterranean SRDAMs has not yet been put into effects in terms of creation of new marine fish farms, and this can be considered as a failure at this stage. On the other hand, the SRDAMs can be regarded as a first experience in France to set up a marine spatial planning, and despite focusing only one activity, it constitutes an interesting opportunity to analyze a process for maritime spatial planning.

\subsection{Stakeholders participation}

\footnotetext{
${ }^{17}$ MEAP : Meilleurs Emplacements Aquacoles Possibles = best sites for aquaculture
} 
The literature about maritime spatial planning insists on the importance of stakeholder participation. But the involvement of stakeholders in the maritime spatial planning process can occur at different levels, as shown by Pomeroy and Douvere (2008) who distinguish six levels in the participation. Using their representation of the range for stakeholders' participation, we attempted to characterize the participation of stakeholders as concerns the Mediterranean SRDAMs (Figure 1). Despite the large work done by the Mediterranean DIRM in the concertation and consultation phases, and in the numerous bilateral contacts, the participation of stakeholders did not concern all stakeholders on the full process. Only the fish farmers were involved up to the highest level "negotiation" leading to final decisions, and the fishermen were just involved up to "dialogue". The other coastal zone users were not consulted directly but mainly through the representation of their concerned public administration, and through the elected representatives at different scales (French region and French Departement). During meetings the public were neither consulted directly but through the mayors of local municipalities and some qualified people from associations. Public opinion could be expressed only by internet during a one-month consultation.

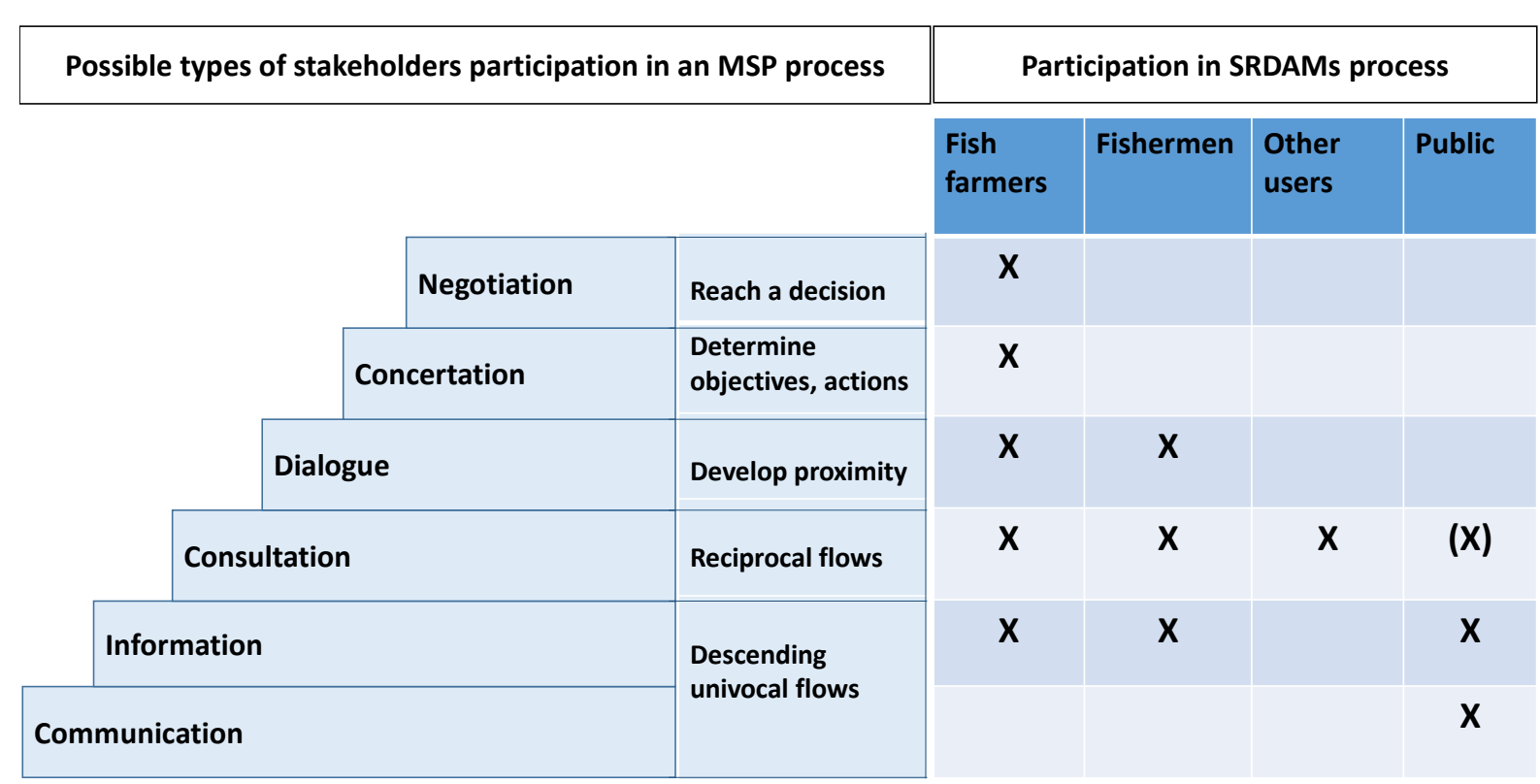

Figure 1 - Attempt to characterize the stakeholders' participation in Mediterranean SRDAMS, using the "possible types of stakeholders participation in an MSP process" proposed by Pomeroy and Douvere (2008)

The choice of this pattern for stakeholders' involvement corresponds to what was planned by the Administrative circular (DPMA, 2011) and can be well understood in the case of the SRDAMs, considering their means and goals. But a wider participation of stakeholders will be necessary for the MSP included for France in the elaboration of the DSF (in progress). As shown by the literature on marine spatial planning, a significant involvement of stakeholders is a key component of the process and a key factor of success for its implementation. About aquaculture zoning, FAO \& World Bank (2015 \& 2017) underline that to solve social conflicts as the lack of public confidence in the sustainability of aquaculture or the competition with other users for space and water, the involvement of relevant stakeholders at all levels of the process allow an improved accountability and transparency. Pomeroy and Douvere (2008) explains that in MSP process, the "empowerment of stakeholders" is essential, and they present the interest of the "social preparation" of stakeholders during the initial phase. They mention a number of participatory tools and methods including focus groups discussions, problem trees and preference ranking. Veidemane and Nikodemus (2015) insist on the need to adopt a broad view in consultation, including land stakeholders in addition to marine stakeholders, when dealing with marine spatial planning that includes activities with some potential visual impacts.

Indeed, what is at stake is the construction of a shared culture about the different marine activities and their respective issues, in addition to common issues for the concerned zone. Marine fish farming is the last comer, still a "new activity" hardly known by other users and coastal communities or even negatively perceived due to negative communication in the media about intensive and impacting aquaculture cases. The challenge in that context is to provide through wide participative approaches the opportunity to become visible and to make social acceptability progress at local scale. 


\subsection{Social acceptability}

While the difficult access to space in the coastal zone has been identified for long as the main factor hampering the development of marine fish farming in France, it is interesting to note that the launching of SRDAMs was interpreted by the professional fish farming sector as a way to improve social acceptability.

In the recent decades, the decrease of social acceptability that strikes the agriculture sector, especially for husbandry, brings some interesting lessons. Delanoue et al. (2015) reviewed the studies done about the opinions and expectations from society stakeholders towards animal husbandry in France, and analyzed them using the tools of sociology of controversies. Interestingly, they show that the debates about animal husbandry are controversies, as defined by Schmoll (2008, in Delanoue et al. 2017), that combine scientific uncertainties, a public opinion with an affect component and antagonism between different groups of stakeholders. In the complex set of debates, they found four main groups of subjects: environmental impact, animal welfare, health (animal and human), and, together, animal farming systems and meat consumption. Although there are differences between the situation of land animal husbandry and that of aquaculture, there are also similarities and the aquaculture sector would indeed benefit from a similar approach: the debates about aquaculture should be recognized as a controversy, showing the need for organizing real debates allowing exchanges between aquaculture stakeholders and other stakeholders. Moreover, the identification of the main subjects focused by the controversy about aquaculture would help to communicate properly, and could contribute to make aquaculture emerge from its current marginal position. And above all, the debate should not be restricted to coastal users or representatives only but should also involve consumer representatives and be more integrated with food policies.

Social acceptability is today a main question for the development of marine fish farming, and would require research work to make light on a major constraint for development. Rey-Valette and Mathe (2017) consider that social acceptability for aquaculture concerns both the territorial acceptability and the acceptability of the techniques and production modes in aquaculture. We would rather propose, especially for marine fish farming, a three-dimension approach where the problem of social acceptability can be described as a system with three interlinked components: a spatial acceptability, an environmental acceptability and the acceptability for farming techniques.

\subsection{Status of zones for aquaculture: suitability, vocation \& priority, allocation}

The SRDAMs provide a framework aiming to map the "suitable sites for aquaculture", by crossing professional and scientific advices, objective criteria and presence of other activities. That framework is a help for further creation of farms, but it gives no right for aquaculture to claim for these zones, due to the weak legal value of SRDAMs. Other statutes for zoning are possible, giving more strength: vocation and priority, and allocation.

Vocation and priority are the bases of the mapping of marine space and coastal land in the PADDUC (Corsica). This system restricts the competition between activities, and gives direction for management.

The FAO General Fisheries Commission for the Mediterranean achieved a long work before reaching the concept of allocated zones for aquaculture (AZA) in marine coastal areas, defined in the Resolution GFCM/36/2012/1. The Article 2 states that "AZAs shall comprise specific areas dedicated to aquaculture activities...". As analyzed by Sanchez-Jerez et al. (2016), the AZA are zones in which "aquaculture has secured use and priority over other activities, and where potential adverse environmental impacts and negative interactions with other users are minimised or avoided". A main key to avoid conflicts with other users is a participatory approach in the spatial planning leading to creation of AZA. The authors describe the cases of numerous countries where AZA have been set up (Malta, Croatia, Greece, New Zealand, Australia, Chile, Canada, Morocco, and Italy and Spain at regional scale), and beyond, also underline the necessary enforcement of regulations for sustainable aquaculture by the relevant authorities. In conclusion to their extensive review, they assess the need of a spatial planning through AZA for developing aquaculture in a context of competition for space in coastal areas. Jeffery et al. (2014) in their recommendations issued from the study about sustainable aquaculture development addressing in particular environmental protection (SUSAQ), also recommended the setting up of AZA.

In France, while there is today a strong political will to develop aquaculture, the question of dedicating some costal zones to fish farming, beyond defining suitable sites, should be considered by the public authorities.

\subsection{Other room for improvement and outlooks}

The inclusion of environmental issues in aquaculture zoning is a key-question. SRDAMs took into account the protection of natural environment in the mapping of existing and suitable sites and the final versions were subject to an environmental assessment, agreed by the Environmental Authority, before final approvals by the regional prefects. Nevertheless, the tension between production growth and protection of the environment remains 
important, as already mentioned. It appeared notably through the opposition from some local associations or NGOs, and even through the weak support of some administration departments.

According to some public and private stakeholders we met, addressing the environmental issues since the beginning of the process would improve the situation. IFREMER is today testing in Mayotte the use of the model DEPOMOD for modelling the deposition and biological effects of waste solids from marine cage farms (Cromey et al., 2002), coupled with the use of a biotic index on benthic biocenosis, in order to predict the environmental impact of marine fish farming. The model DEPOMOD is already included in the regulation of some countries (Canada \& Scotland, source Ifremer 2017). More generally, the compliance of aquaculture zoning and management with the carrying capacity approach, which is at the basis of the Ecosystem Approach for Aquaculture (EAA) (FAO and World Bank 2008), must be considered.

Also, the question of time deserves attention. One aspect well identified in numerous EU countries in 2009 (Hedley and Hutington) relates to the administrative burden, but it is still largely quoted in our study. It is planned to be addressed in the French PSNPDA ${ }^{18}$ 2014-2020. Another aspect is the gap between the short-term needs of the French marine fish farming sector for a facilitation of development, and the long term work required by public policies. The SRDAMs, despite a dedicated policy early initiated, required several years and did not fulfilled the sector needs. The MSP, as a holistic approach should allow a maturation of relationships among users of coastal zone and may improve the place of aquaculture, but is a long process.

\section{Conclusion}

The SRDAMs published in 2015 have not yet allowed further development of marine fish farming in the Mediterranean coast, but our analysis shows that other obstacles to the development of production should be considered and removed. Moreover, the SRDAMs are a national instrument that was created early compared to some European directives like MSP and MSFD and there is a need to (re)consider and analyze their place among these policies.

Acknowledgements: this study is part of the European research program SUCCESS (Horizon 2020, 201518).

\section{References :}

Anonymous, 2015 - Schéma régional de développement de l'aquaculture marine Corse. Préfecture de la région Corse. 31 pp.

Anonymous, 2015 - Schéma régional de développement de l'aquaculture marine Languedoc-Roussillon. Préfecture de la région Languedoc-Roussillon. 37 pp.

Anonymous, 2015 - Schéma régional de développement de l'aquaculture marine Provence-Alpes-Côte d'Azur. Préfecture de la région Provence-Alpes-Côte d'Azur. 35 pp.

Anonymous, 2015 - Synthèse du PADDUC. Collectivité Territoriale de Corse. 50 pp.

Anonymous, 2015 - PADDUC, Chapitre individualisé valant Schéma de Mise en Valeur de la Mer, Livre I: Diagnostic et Enjeux. Collectivité Territoriale de Corse, Agence Aménagement Urbanisme Energie.

Anonymous, 2015 - PADDUC, Chapitre individualisé valant Schéma de Mise en Valeur de la Mer, Livre II : Orientations \& Prescriptions. Collectivité Territoriale de Corse, Agence Aménagement Urbanisme Energie. $176 \mathrm{pp}$.

Anonymous, 2015 - Cartes PADDUC SMVM, 10 Vocations, 11 Enjeux, 12 Menaces, 13 Potentialités. Collectivité Territoriale de Corse. http://www.aue.corsica/Travaux-en-cours_r25.html

Cromey C. J., Thomas D Nickell T.D., Black K.D., 2002 - DEPOMOD — modelling the deposition and biological effects of waste solids from marine cage farms. Aquaculture, 214, 1-4, 211-239.

Delanoue E., Dockes A.C., Roguet C., Magdelaine P., 2015 - Points de vue et attentes des acteurs de la société envers l'élevage. Un regard sur les principales controverses. Actes du Colloque 3R, Paris : France, 8 pp.

EU Commission, 2016 - Summary of the 27 Multiannual National Aquaculture Plans. 12 p.

FAO \& World Bank. 2015. Hedley C., Huntington T., 2009 - Regulatory and legal constraints for European aquaculture. Ocean Law Information and Consultancy Services \& Poseidon Aquatic Resources Management. Study for the European Parliament's Committee on Fisheries. 102p.

\footnotetext{
${ }^{18}$ PSNPD (plan stratégique pluriannuel de développement aquacole) : strategic pluriannual plan for development
} of aquaculture 
FAO \& World Bank, 2015 - Aquaculture zoning, site selection and area management under the ecosystem approach to aquaculture. Policy brief. Rome, FAO. 4p.

FAO \& World Bank. 2017. Aquaculture zoning, site selection and area management under the ecosystem approach to aquaculture. A handbook. Rome, FAO. 75p.

GFCM, 2012 - Resolution GFCM/36/2012/1 on guidelines on allocated zones for aquaculture. In: Report of the $36^{\text {th }}$ Session, Marrakech, Morocco, 14-19 May 2012. General Fisheries Commission for the Mediterranean, FAO.

Hedley C, Huntington T (2009) Regulatory and legal constraints for European aquaculture. European Parliament, Directorate General for Internal Policies, $102 \mathrm{pp}$.

IFREMER, 1999. Inventaire des zones d'aptitude aquacole du littoral français. Vol. 2 : pisciculture. 17 p. + annexes.

Jeffery, K.R., Vivian, C.M.G., Painting, S.J., Hyder, K., Verner-Jeffreys, D.W., Walket, R.J., Ellis, T., Rae, L.J., Judd, A.D., Collindridge, K.A., Arkell, S., Kershaw, S.R., Kirby, D.R., Wattas, S., Kershaw, P.J., \& Auchterlonie, N.A., 2014 - Background information for sustainable aquaculture development, addressing environmental protection in particular. Sub-Title: Sustainable Aquaculture Development in the context of the Water Framework Directive and the Marine Strategy Framework Directive. Part 1 Main Report \& References. 156 pp. Part 2 Annexes \& supporting documents. 182 pp.

Maurin A., Bouchoucha M., Sauzade D., 2007 - SI REMCO : Système d'Information pour l'exploitation durable des REssources Marines Corses. Création d'un outil cartographique d'aide à la décision pour l'implantation de fermes piscicoles sur le littoral corse. IFREMER LER-PAC. 166 pp.

Pomeroy R., Douvere F., 2008 - The engagement of stakeholders in the marine spatial planning process. Marine Policy 32 (2008) 816-822.

Rey-Valette H., Mathe S., 2017 - La notion d'acceptabilité sociale : de quoi s'agit-il et comment peut-on intervenir ? In- Le Gouvello R. \& Simard F. (eds) (2017) - Durabilité des aliments pour le poisson en aquaculture. Réflexions et recommandations sur les aspects technologiques, économiques, sociaux et environnementaux. Gland, Suisse : UICN, et Paris, France : Comité français de l’UICN. 296 pp. 72-76.

Sanchez-Jerez, P., Karakassis, I., Massa, F., Fezzardi, D., Aguilar-Manjarrez, J., Soto, D., \& Marino, G. (2016). Aquaculture's struggle for space: the need for coastal spatial planning and the potential benefits of Allocated Zones for Aquaculture (AZAs) to avoid conflict and promote sustainability. Aquaculture Environment Interactions, 8, 41-54. 